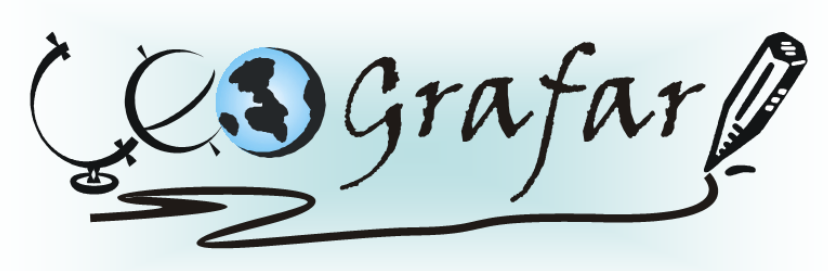

Revista Eletrônica do Programa de Pós-Graduação em Geografia - UFPR

\title{
COMUNIDADES DE FAXINAL E SUAS DINÂMICAS SÓCIO-ESPACIAIS: DA FORMAÇÃO À DESAGREGAÇÃO DE UMA TRADIÇÃO NO MUNICÍPIO DE TIBAGI (PR) - UM ESTUDO SOBRE O FAXINAL DOS EMPOÇADOS
}

\author{
DOUGLAS GRZEBIELUKA ${ }^{1}$ \\ CICILIAN LUIZA LÖWEN SAHR ${ }^{2}$
}

Resumo: Este artigo busca analisar as transformações sócio-espaciais de comunidades rurais de Tibagi (PR), especialmente do Faxinal dos Empoçados, cuja estrutura de ocupação apresentou e/ou ainda apresenta características de Faxinal. Através do resgate histórico procura-se compreender os processos que ocasionaram a formação e a ruptura deste modelo singular de desenvolvimento agrosilvipastoril - o Sistema Faxinal. Na dinâmica econômica vivenciada por Tibagi, desde os seus primórdios até a atualidade, as comunidades de faxinal apresentaram seu auge no período do chamado "Tropeirismo de Porco". A partir de então, a modernização da agricultura e da sociedade foi introduzindo processos homogeneizantes que pouco lugar deixava as comunidades tradicionais, levando a uma desagregação desta tradição no Município.

Palavras-Chaves: Faxinais, dinâmica sócio-espacial, Tibagi (PR).

\section{COMMUNITIES OF FAXINAL AND THEIR SOCIAL-SPACE DYNAMICS: FROM THE FORMATION TO THE DISAGGREGATION OF A TRADITION IN THE MUNICIPAL DISTRICT OF TIBAGI (PR) - A STUDY ON FAXINAL DOS EMPOÇADOS}

\begin{abstract}
This article analyses the social-space transformations of rural communities from Tibagi (PR), especially from Faxinal dos Empoçados, whose structure of occupation presented and / or still presents characteristics of Faxinal (This System consists in small rural communities which combine agriculture, animal raising and extractive activities on a community land, besides a strong focus on subsistence agriculture). Through the historical recovering, we tried to understand the processes that caused the formation and the break of this singular model of agrosilvopastoral development- the Faxinal System. In this dynamic economic experienced by the Municipality, from its origins up to the present, the communities of faxinal presented its height in the period of the "Tropeirismo (system based on drivers of pack animals, muleteers) of Pig". From then, the process of agriculture modernization and of the society was introduced in a homogenizing processes that little place was left to the traditional communities, leading to a disaggregation of this tradition in the Municipal district.
\end{abstract}

Key-words: Faxinais, social-space dynamics, Tibagi (PR).

\footnotetext{
${ }^{1}$ douglasgebeluka@bol.com.br

2 cicilian@uol.com.br
} 


\section{INTRODUÇÃO}

Nas últimas décadas, as discussões sobre a agricultura brasileira têm se tornado parte constitutiva da agenda política mundial pela importância vital que desempenha no campo político e econômico. Com o baixo crescimento econômico, alto desemprego e a elevada taxa de juros existe uma tendência à concentração da distribuição funcional e pessoal da renda. Assim, devido à acumulação de capital e a escassez de trabalho, o desenvolvimento permanece desigual e quem sofre com isso é a camada mais pobre da população. Entende-se com isso, que o sistema capitalista reflete uma sociedade em que os conceitos de desenvolvimento favorecem apenas os que detêm o capital; pois as políticas econômicas desenvolvimentistas, trazem consigo ações que reproduzem simultaneamente uma sociedade dual, onde aumenta a concentração de riqueza e expande-se a pobreza.

Pouco se faz no sentido de buscar um "desenvolvimento sócio-espacial" (SOUZA, 2006), onde prevaleçam aspectos como maior justiça social e melhor qualidade de vida. A modernização agrária provoca seus efeitos perversos, entre eles, o agravamento da desigualdade de renda, a concentração da terra nas mãos de latifundiários, a queda da competitividade e vulnerabilidade da cultura familiar e a degradação do meio ambiente.

Nas Matas Mistas com Araucária do Paraná, desenvolveu-se - durante seu processo de ocupação - um sistema agrosilvipastoril singular - o Sistema Faxinal, que apresenta entre seus componentes o criadouro comunitário, a extração florestal e o cultivo agrícola, além de expressões culturais e religiosas particulares. Apesar de todas as atrocidades sofridas pelas comunidades organizadas neste sistema, existe ainda um número pequeno destas, mas significativo, embora suas áreas venham sofrendo redução significativa. As comunidades que ainda persistem com todos os seus componentes característicos ativos vivem a mercê da própria sorte, uma vez que só são lembradas de período em período, quando atendem aos interesses de camadas privilegiadas da sociedade política. Essas comunidades enfrentam pressões externas, sobretudo dos grandes latifundiários e empresários, os quais trazem em suas ações apenas o aspecto lucrativo da terra.

Desde a sua gênese, as comunidades de Faxinal vêm mostrando uma capacidade impar de adaptação à dinâmica econômica das regiões onde estão inseridas, entretanto, se assiste também a um processo de desagregação deste modo de viver, o qual vem perdendo seus laços 
históricos, sociais e culturais do passado. O avanço das frentes de tecnologia agrícola vem atingindo estas comunidades, algumas se integram ao sistema de agricultura industrial, mantendo a terra; em outras há a venda gradativa das terras para latifundiários e a conseqüente migração dos faxinalenses.

Neste sentido, o presente artigo busca analisar as transformações sócio-espaciais de comunidades rurais do Município de Tibagi (PR), especialmente do Faxinal dos Empoçados, cuja estrutura de ocupação apresenta componentes característicos de Faxinal.

Metodologia: Para atingir os objetivos propostos por este artigo, utilizou-se como metodologia a revisão da bibliografia regional, buscando uma leitura sistemática que ressaltasse os principais pontos pertinentes ao assunto. Recorreu-se a um levantamento histórico da origem dos Faxinais no Paraná e da estruturação agrária do município de Tibagi (PR), buscando subsídios para a compreensão dos processos que ocasionaram a formação de uma estrutura agrária dual - de um lado grandes latifúndios e de outro pequenas comunidades rurais. A análise de mapeamentos das localidades rurais de Tibagi (PR), também contribuiu para a compreensão da estrutura de ocupação e povoamento deste município.

$\mathrm{O}$ artigo se encontra estruturado da seguinte forma: em um primeiro momento faz-se uma abordagem mais abrangente referenciando os Faxinais, trazendo sua definição bem como a trajetória histórica destas comunidades no Estado do Paraná: da gênese a desagregação. Na sequência apresenta-se uma análise contextual relatada através de fatos históricos que marcaram a ruptura deste sistema nas terras do município de Tibagi (PR). Por fim, a análise se volta para a trajetória da comunidade denominada Faxinal dos Empoçados. Para analisar a trajetória específica deste faxinal foi realizada visita a localidade, ocasião em que se entrevistaram alguns dos moradores mais antigos da região, buscando o resgate oral da história da comunidade, e também a professora e pesquisadora Dircéia Eidam, a qual já realizou estudos referentes às localidades rurais do Distrito de Alto do Amparo - Tibagi (PR). As entrevistas foram gravadas e posteriormente transcritas como forma de facilitar a compreensão da dinâmica sócio-espacial vivenciada pela localidade. 


\section{COMUNIDADES DE FAXINAIS: DA GÊNESE A DESAGREGAÇÃO}

No decorrer dos diferentes ciclos econômicos vivenciados na dinâmica sócio-espacial brasileira surge, na região de matas mistas do Paraná ou Mata com Araucária, um sistema agrosilvipastoril típico, que vivencia seu auge com a fase de exploração da erva-mate - o Sistema Faxinal.

Este Sistema define-se como sendo uma forma harmônica de utilização de áreas interligadas e cobertas por vegetações de Floresta com Araucárias; estas áreas permitem o uso de criadouros extensivos e comuns, ou seja, coletivos ou comunitários, bem como, extração de erva mate e de algumas espécies vegetais para consumo, como fonte de energia ou outras atividades de interesse comunitário para a geração de renda (CHANG, 1988a).

De maneira geral, entende-se por Faxinal faixas de mato denso, entretanto:

No Paraná o termo é utilizado para indicar uma área silvopastoril delimitada, dentro da qual se encontra um povoamento e sobre a qual circulam livremente animais pertencentes a esta comunidade. Trata-se tanto de animais de grande porte: bovinos, equiinos e muares, como também de pequeno porte: suínos, caprinos, ovinos e aves, além de animais domésticos. (LÖWEN SAHR, 2007, p. 208).

Este sistema "sustenta-se essencialmente sobre a pequena produção animal, a policultura alimentar e o extrativismo do mate". (CHANG, 1988b, p. 45). Sendo o que lhe difere dos demais sistemas de agricultura, é a forma singular de uso da terra. Os Faxinais apresentam os seguintes elementos, que também estão presentes em outras atividades que envolvem a produção familiar:

Produção animal - criação de animais domésticos para tração e consumo com destaque às espécies eqüina, suína, caprina, bovina e aves; produção agrícola policultura alimentar de subsistência para abastecimento familiar e comercialização da parcela excedente, destacando as culturas de milho, feijão, arroz, batata e cebola; coleta da erva-mate - ervais nativos desenvolvidos dentro do criadouro e coletados durante a entressafra das culturas, desempenhando papel de renda complementar. (CHANG, 1988b, p. 13).

O sistema de organização e produção em Faxinais possui características específicas diferenciadas dos sistemas de exploração predominante. Vale ressaltar que neste sistema de 
harmonia, o uso da terra dentro dos limites do criadouro é comum, mas a propriedade sobre a mesma permanece sendo privada. Esta característica singular desse sistema, marcante, em relação a outras formas de produção agrícola, é o que lhe diferencia dos demais. Essa organização e produção possuem uma centralidade social voltada ao homem, caracterizando-o como sujeito principal do sistema (CHANG, 1988a).

Para se ter idéia da importância deste sistema na dinâmica sócio-espacial do Paraná, acredita-se que os Faxinais já ocuparam um quinto do território paranaense, e por isso demandam ações voltadas à conservação, tendo em vista a sua importância social, cultural e ambiental (CHANG, 1988; SOUZA, 2001; MARQUES, 2004 e LÖWEN SAHR; CUNHA, 2005).

A estrutura típica do sistema faxinal consiste na divisão do solo em duas parcelas: as terras de plantar e as terras de criação. As terras de criação também são conhecidas como criadouro comum ou terras de faxinal. (CHANG, 1988 e LÖWEN SAHR; CUNHA, 2005). No criadouro comum, área cercada que caracteriza o sistema de uso comum da terra, estão localizadas as residências, é onde os animais se criam soltos, buscando na natureza sua alimentação; espaço de onde colhem erva-mate e retiram a madeira. A área que abrange o criadouro comum é um espaço de harmonia coletiva, no qual a terra é partilhada, mas a propriedade sobre a mesma conserva-se de forma individual; a manutenção desse espaço é de responsabilidade coletiva. As terras de plantar, são os espaços onde se pratica uma agricultura de subsistência, desenvolvem-se as lavouras, as roças; estas terras podem ser particulares ou arrendadas, nas quais o cultivo desenvolve-se individualmente, não dependendo de outras pessoas. (CHANG, 1988a, p. 06 e LÖWEN SAHR; CUNHA, 2005, p. 95).

As estruturas dos faxinais e sua organização resultam do modelo de como se estruturavam as antigas fazendas. Nestas se criava animais a solta e se cercava a produção. $\mathrm{O}$ sistema faxinal organizou-se forma particular, ou melhor dizendo, contrário a organização das fazendas; cercava-se os animais em uma grande área - criadouro comum - e plantava-se fora dos limites do criadouro - terras de plantar. (CHANG, 1988b, p. 25 a 28).

O criadouro se sustenta com base em três proposições: "A propriedade da terra, a construção da cerca e o zelo da mesma”. (CHANG, 1988b, p. 38). A concepção das cercas do criadouro acabou por beneficiar todos os envolvidos na dinâmica agrícola; os fazendeiros, 
agregados e colonos; fato este que fez com que o número de criadouros se multiplicasse por toda a região. (CHANG, 1988b, p. 39).

O ambiente natural destacou-se como sendo o fator decisivo para o surgimento e implantação do sistema faxinal (SOUZA, 2001, p. 02). A localização dos faxinais depende de alguns elementos físicos da paisagem, os quais muitas vezes facilitam a organização territorial deste sistema:

Os Faxinais encontram-se, geralmente, nos vales de pequenos arroios e são delimitados por valos e cercas comunitários. As estradas de terra que o cortam utilizam-se de recursos como porteiras e mata-burros, geralmente de madeira, os quais tem a função de impedir a fuga de animais. Não muito distante das estradas encontram-se - dispersas nos espigões dos terraços mais altos casas de madeira. Em cada uma habita uma família nuclear. (LÖWEN SAHR, 2007, p. 214).

Em relação à localização territorial dos Faxinais pode-se dizer que a maioria foi fruto das condições naturais da região Centro-Sul do Paraná. Esta é uma região que possui em abundância as Matas Mistas com Araucárias; estas matas são ricas em erva-mate, principal produto que sustentou e configurou a estrutura dos faxinais. Também há indícios desse sistema nos estados de Santa Catarina e Rio Grande do Sul, porém, a sua permanência tornase impossível devido ao alto grau de modernização agrícola da região, a qual recebe altos investimentos no setor. (CHANG, 1988b, p. 49).

A gênese dos faxinais deriva do sistema de "agregados" das grandes fazendas. Após o ciclo da mineração do ouro, muitos dos homens que trabalhavam de mineiros, tornaram-se homens livres os quais se estabeleceram nas regiões onde a vegetação era predominantemente de Campos. Como forma de sobreviver praticavam uma agricultura de subsistência; e em tempos de colheita da erva-mate, circulavam por fazendas como mão-de-obra subordinada aos grandes fazendeiros. (CHANG, 1988b, p. 21).

A categoria dos agregados constituía o grosso dos trabalhadores na coleta da erva, inclusive afluindo para a região das matas mistas do Centro-Sul, estabelecendo-se nos ervais com sua economia de subsistência; constituindo comunidades rurais as quais mais tarde dariam origem aos faxinais. (CHANG, 1988b, p. 21). 
Os agregados “[...] possivelmente descapitalizados, se apossavam de pequenos lotes em terras de donos não declarados e se empregavam na construção e reparo de cercas e no preparo da lavoura de milho destinado a alimentação animal" (SOUZA, 2001, p. 44).

O agregado nada mais era do que um posseiro, que se encontrava na terra antes de ela ser requerida por alguém. Quando chegava um senhor e se dizia proprietário de uma determinada porção de terras onde se encontravam alguns posseiros, estabelecia-se uma relação de troca entre ambos. Esta relação se processou de diferentes formas Brasil. (BARRETO; LÖWEN SAHR, 2007, p. 77).

Os agregados contribuíram decisivamente na gênese formadora da estrutura fundiária do Centro-Sul paranaense, bem como os imigrantes europeus (poloneses, italianos e alemães) que chegavam ao Brasil e iam conquistando o interior nas regiões de Matas Mistas com Araucárias. Estes imigrantes rapidamente absorveram o sistema de exploração da erva-mate; é nesse contexto que o sistema faxinal, sobre a forma de organização camponesa ganha destaque. Com o aumento da produção agrícola, não havia meios de deixar os animas se criarem à solta, neste momento inicia-se a construção de cercas coletivas, surge então o criadouro comum. (CHANG, 1988b, p. 37-38).

Neste contexto, Schuster (2007, p. 13) aponta que: “O Sistema Faxinal é fruto de uma época onde sua formação era lucrativa para todos os seus integrantes, desde o fazendeiro até o agregado."

Para Löwen Sahr e Cunha (2005, p. 93), a gênese formadora do sistema faxinal, está no momento em que os Bandeirantes adentram os campos do Paraná e expulsam índios e jesuítas de suas Reduções; sendo que os índios espalharam-se pelos campos. Na sequência temos início à fase dos Tropeiros. Novamente os remanescentes de Kaigang adentram as matas, onde também vaqueiros, bandeirantes e escravos se encontravam; é o momento que surge o novo sistema de subsistência: os faxinais.

Nos faxinais tem-se o caboclo como sendo o principal grupo que compõe a estrutura racial deste sistema. (CHANG, 1988b, p.18). Barbosa (2007, p. 46) em seus estudos sobre os Faxinais de Rio Azul (PR), constatou “[...] a presença de traços europeus até semblantes indígenas no perfil dos faxinalenses do Taquari dos Ribeiros”. 
Não tendo data precisa nem o principal agente desagregador, as estruturas dos faxinais começam a romper a partir do momento em que forças capitalistas adentram as terras desta organização camponesa; estas forças capitalistas dedicam-se a exploração de mão de obra barata e a comercialização de produtos de fabricação artesanal, muitas vezes em função de um rendimento mínimo exploram e degradam o modo simples de viver destas comunidades. Atualmente existem três tipos de situações com relação aos Faxinais: os que permaneceram com o "Sistema Faxinal Coletivo e Original", os Faxinais que permanecem apenas com a paisagem de "Matas de Araucária", e os Faxinais que existiram e hoje são apenas comunidade de agricultores individuais, que não resistindo às pressões externas aderiram ao novo modelo produtivo e, conseqüentemente, perderam sua identidade enquanto organização campesina (MARQUES, 2004, p. 09).

Os faxinais mais antigos possuem mais de um século de existência. O auge desse sistema foi à atividade ervateira, que se desenvolveu nas regiões de matas mistas. Através desta atividade organizou-se a estrutura econômica do sistema faxinal, onde o excedente de produção era absorvido por um mercado em plena expansão. (CHANG, 1988b, p. 14-15).

No Paraná, constata-se que existiram pelo menos 152 Faxinais no Paraná. Atualmente apenas 44 destes são considerados Remanescentes, ou seja, mantêm a organização social típica do sistema; 56 estão Desativados, ou seja, preservam apenas a paisagem de faxinal em Matas com Araucária; e 52 estão Extintos, ou seja, perderam totalmente suas características originais. (MARQUES, 2004, p. 15 e LÖWEN SAHR; CUNHA, 2005, p. 95). Sendo que as terras de faxinal encontram-se "localizadas em 16 municípios do Paraná pertencentes ao bioma da Mata de Araucária. As áreas de uso comum totalizam 15.915 hectares. Os povos de faxinal agregam um total de 3.454 famílias.” (LÖWEN SAHR, 2005, p. 56).

Marques (2004, p. 190) ressalta que:

[...] os faxinais na sua totalidade, estão ou continuam em processo de desagregação, alguns de forma lenta, outros mais acelerados e outros totalmente desagregados [...]. Observou-se que esta situação tem se agravado a cada ano que se passa, apesar da legislação que ampara estes sistemas.

Pode considerar-se que o início da desagregação deste sistema inicia-se por volta de 1930 com a exploração madeireira de forma depredatória. Os ervais nativos, muitas vezes, 
acabavam sendo destruídos com o corte dos pinheiros sendo que a coleta da erva-mate representava a principal fonte de renda das comunidades faxinalenses. A partir de 1960, a agricultura brasileira passa por profundas alterações. Inicia-se uma política de incentivo a modernização agrícola; esta modernização ocorre de maneira desigual, estando voltada a investimentos na produção para a exportação (CHANG, 1988a, p.15).

Diante do quadro exposto, pode-se considerar que toda esta situação contribuiu de forma decisiva no início da desagregação dos faxinais, que ocorrem de duas formas:

- abandono da criação a solta, iniciando-se pela miúda e estendendo-se gradualmente a graúda;

- diminuição da área total dos criadouros, devido à saída (do condomínio) de alguns proprietários desinteressados em criar à solta; (CHANG, 1988b, p. 78).

Chang (1988b) enfatizou também a onda migratória e a relação com a desagregação dos sistemas faxinais e a fundamentação da modernidade tecnológica, o que foi reforçado nos estudos de Souza (2001) quando pesquisou os Faxinais de Turvo - PR. Souza (2001, p. 61), constatou em suas pesquisas que o início da desagregação se dá com a instalação de madeireiras, estas somente compravam os pinheiros, depredando a natureza local.

Outro fator de destaque em relação à desagregação deste sistema é um aumento considerado, no número de integrantes das unidades familiares nos espaços tradicionais deste sistema. Este fato tem gerado um adensamento sobre o solo, ocasionando a escassez da terra e dificuldades na organização sócio-espacial dos faxinais. (MARQUES, 2004, p. 190).

Em relação a esta situação Barbosa (2007, p. 28) destaca que:

O fato é que se torna necessário uma rotatividade populacional no Faxinal, o que em outras palavras significa que não há espaço físico para todos os descendentes no território faxinalense, o que demanda um êxodo, não necessariamente para o meio urbano.

O sistema faxinal garantiu "[...] por mais de meio século, a sustentabilidade sócioambiental da produção familiar com o ambiente florestal, permitindo uma relativa autonomia aos agricultores camponeses (SOUZA, 2001, p. 03). Acredita-se que apesar das pressões capitalistas, os caboclos do sistema faxinal têm conseguido manter-se afastado das modernas 
técnicas que invadem o campo. Destacam que “[...] os faxinais merecem mais atenção, pois representam uma forma bastante antiga de uso da terra (se não a mais antiga) do Brasil Colonial" (LÖWEN SAHR; CUNHA, 2005, p. 90).

A desarticulação dos Sistemas Faxinais tem implicações econômicas, sociais, ambientais, políticas e culturais para os camponeses, que passam a deixar de ter a relação que antes tinham com a terra, e que referenciava também a sua concepção de mundo. Löwen Sahr e Iegelski (2003), afirmam isto após verificar a intensa desagregação dos Faxinais localizados no distrito de Itaiacoca, no município de Ponta Grossa.

A exploração da madeira, modernização da agricultura, falta de políticas públicas, aumento da produção agrícola invadindo a área do criadouro, esgotamento dos recursos naturais, elevado preço da terra, estes são apenas alguns indicadores que podemos citar como possíveis agentes de desestruturação do sistema faxinal, sendo que tudo isso se resume "no avanço das forças capitalistas de produção no campo.” (CHANG, 1988b, p. 78).

Quando as forças capitalistas, ou seja, as explorações da terra e do camponês adentram as fronteiras do faxinal, as estruturas deste sistema começam a sofrer algumas transformações, que se resumem nas seguintes palavras de Barreto e Löwen Sahr (2007):

[...] o capital se expande de duas formas nas terras dos Faxinais: uma forma territorializada, quando as fazendas vizinhas incorporam as terras pertencentes aos criadouros comunitários e acabam destinando-as à monocultura; e outra quando o capital não se territorializa, mas monopoliza o território alheio através da extração da renda da terra e da sujeição da força de trabalho camponesa. (BARRETO; LÖWEN SAHR, 2007, p. 76).

A falta de políticas que garantam o acesso a terra é um dos fatos que se apresentam como fator de desagregação dos faxinais (LÖWEN SAHR; CUNHA, 2005, p. 96). Os agricultores não resistem às pressões por falta de incentivos e acabam vendendo suas terras a grandes fazendeiros, estes por sua vez, quando adquirem terras que invadem a área do criadouro, acabam desarticulando as estruturas tradicionais do sistema faxinal, sem falar na implementação de modernas técnicas agrícolas.

A desagregação dos faxinais traz consigo consequiências que abrangem todo o sistema socioeconômico; o qual acaba por necessitar de políticas públicas para sua (re)organização e que atenda o interesse das classes envolvidas. No Paraná algumas ações já estão sendo 
visualizadas no campo das políticas públicas, como por exemplo, o Decreto Estadual $\mathrm{n}^{\circ}$ 3.446/1997, que reconhece o sistema faxinal como uma forma de organização camponesa. (LÖWEN SAHR; CUNHA, 2005, p. 97).

A manutenção desses espaços é extremamente importante para as futuras gerações, do ponto de vista histórico e social, tendo em vista que ainda existem Faxinais em condições originais no Centro-Sul do Paraná. Existe a necessidade de medidas públicas urgentes quanto à conservação desses espaços, em virtude da pressão econômica exercida pelo sistema capitalista de exploração que vem colocando em risco o futuro desses ambientes e sua forma de organização. (CHANG, 1988; SOUZA, 2001; MARQUES, 2004 e LÖWEN SAHR; CUNHA, 2005).

Para Marques (2004, p. 191):

\begin{abstract}
Mudanças são necessárias dentro dos faxinais, pois é imprescindível se buscar propostas mais sustentáveis, principalmente na área econômica (de geração de renda), social e ambiental. E, apesar dos diversos problemas que estão ocorrendo nos faxinais, com as famílias residentes e/ou com o sistema, ainda existem possibilidades concretas de se implementar alternativas sustentáveis, como a agroecologia, visando à manutenção dos mesmos; dependendo, às vezes, só de pequenos apoios estruturais e estratégicos".
\end{abstract}

As comunidades tradicionais modificam-se de acordo com a dinâmica interna e externa da sociedade, mas segundo Diegues $(1999$, p. 13) “[...] em um ritmo mais lento". Considerase que as comunidades de faxinal, atendem as perspectivas de desenvolvimento sustentável. Com suas características tradicionais, esse sistema tem no meio ambiente as fontes do sustento de suas atividades, as quais exploram de maneira racional, de forma a garantir a existência destes recursos por sucessivas gerações.

\footnotetext{
Esses sistemas tradicionais de não são somente formas de exploração econômica dos recursos naturais mas revelam a existência de um complexo de conhecimentos adquiridos pela tradição herdada dos mais velhos, de mitos e simbologias que levam a manutenção e ao uso sustentado dos ecossistemas naturais. (DIEGUES, 1999, p. 267).
}

Considerando o valor social, econômico, cultural e ecológico que as comunidades tradicionais preservam, iniciativas tornam-se necessárias para a manutenção das comunidades 
tradicionais. Löwen Sahr e Cunha (2005), bem como, Löwen Sahr (2007), consideram os Faxinais como uma das mais importantes vias de desenvolvimento sustentável e de preservação da Mata com Araucária:

Com a crescente ameaça à Mata com Araucária através do aumento das áreas da agricultura moderna, acredita-se que os Faxinais, por apresentarem características da formação natural desta vegetação. Podem contribuir para a proteção e preservação desta. Por esse motivo, o Sistema Faxinal pode ser visto como uma forma de uso mais sustentável, que preserva a Mata do Pinheiro do Paraná sem renunciar totalmente ao uso deste ecossistema. (LÖWEN SAHR; CUNHA, 2005, p. 101-102).

Os faxinais podem ser considerados como sendo o sistema agrícola que tem sua base na sustentabilidade ambiental e que "[...] alguns ainda mantém essa função - como diques de contenção ao avanço da degradação ambiental sobre a floresta de araucária." (SOUZA, 2001, p. 36). A diversificação das atividades produtivas ajuda na conservação do solo e na proteção da vegetação, permitindo assim retorno econômico aos faxinalenses bem como a manutenção do ecossistema.

De acordo com Diegues (1999, p. 12):

A forte dependência dos recursos naturais, a estrutura simbólica dessas comunidades, seus sistemas de manejo desenvolvidos ao longo do tempo e, muitas vezes, seu isolamento, fazem com que possam ser parceiras necessárias aos esforços de conservação.

As políticas para o desenvolvimento rural nada trazem de novo, a não ser o camuflado discurso de desenvolvimento sustentável. Mas, o desenvolvimento do meio rural continua de forma avassaladora, com políticas que sustentam o incremento tecnológico do campo, deixando para traz pequenos agricultores e camponeses arrasados, vítimas de políticas que beneficiam os grandes produtores. (SOUZA, 2001, p. 37-38).

Ferreira (2008, p. 106) aponta que:

Para manutenção dos faxinais que restaram no Paraná precisa-se pensar com os faxinalenses, em formas de criar uma proteção legal para a totalidade do sistema e alternativas de uso sustentável dos recursos naturais. A produção orgânica de carne de porco, cabra, boi, frango, carneiro e de produtos agrícolas; a apicultura; o leite e derivados; as compotas, geléias e conservas; as hortaliças, etc.; o plantio de 
araucárias; o manejo de erva-mate e plantas medicinais; bem como o turismo comunitário, podem ser atividades complementares para se chegar ao propósito intentado.

Para que isto ocorra, Löwen Sahr (2007, p. 17) salienta que: “[...] o sistema da agricultura precisa ser entendido não apenas como um sistema de produção, mas também como uma forma de expressão sociocultural.” Essas comunidades enfrentam pressões da comunidade externa, ou seja, dos grandes poderios econômicos que trazem em suas ações apenas o aspecto lucrativo da terra. Dada a constante ameaça à sobrevivência dessa forma de uso da terra, torna-se imprescindível centrar esforços para delinear diretrizes para sua preservação e revitalização.

\section{ESTRUTURAÇÃO AGRÁRIA DO MUNICÍPIO DE TIBAGI (PR): UMA ANÁLISE HISTÓRICA}

As terras, de relevo acidentado, que formaram o atual município de Tibagi eram recobertas por Campos e gigantesca Floresta de Araucária. Estas terras foram desbravadas por pioneiros que se aventuravam nos sertões inóspitos do nosso Brasil; estes aventureiros tinham um propósito em comum: descobrir as riquezas do interior brasileiro; e desde os primórdios havia a notícia de que no leito do rio Tibagi encontrava-se ouro e diamante.

A região que formou o Município de Tibagi, "teve o seu solo palmilhado pelos pioneiros de nossa nacionalidade desde as décadas que seguiram à chegada de Cabral às terras de Santa Cruz" (MERCER; MERCER 1977, p. 7), destacando-se: Aleixo Garcia, José Sedenho, D. Alvar Nunes Cabeça de Vaca, Ulderico Schmidl, Fernão Dias e os Jesuítas. Estes exerceram sua função por duas décadas em terras tibagianas. (MOTA, 1996). Os Jesuítas espanhóis, na tentativa da conquista de novos territórios, foram estabelecendo suas Reduções ao longo da porção leste do Paraguai e do Peru. Neste contexto ao desbravarem as terras ao longo do rio Tibagi, na altura dos Campos Gerais, os Jesuítas estabelecem a Redução de São Miguel, sobre a coordenação dos padres de Loyola. Nesta redução reuniram índios Guaranis, Caíuas ou Cainguas e Arés, para os quais ministravam fervorosamente os seus ensinamentos cristãos (MERCER; MERCER, 1977, p. 11-13).

Tibagi tem na sua gênese formadora uma fase de ocupação por índios Tupi-Guarani e também Kaingangs, os quais permaneceram com o domínio deste território até o ano de 1632, 
defendendo tenazmente suas terras contra o invasor (MERCER; MERCER, 1977). Estes deram origem ao nome do rio Tibagi, que posteriormente foi incorporado à denominação do município. Com a descoberta de ouro e diamante no leito deste rio, todavia, Tibagi fica conhecido desde 1754, como o "Eldorado Paranaense” (MERCER; MERCER, 1977, p. 22).

Expedições e bandeiras, no início do século XVIII, estabeleceram-se ao longo deste rio em busca de ouro, diamante e também escravos. A partir de então, foram arrasadas as Reduções Jesuíticas instaladas no vale do Tibagi. Várias e sangrentas foram às batalhas até que os índios se rendessem aos ataques do invasor. Índios e Jesuítas, das Reduções de São José e São Francisco, que resistiram aos ataques dos Bandeirantes, adentraram as matas do sertão tibagiano buscando novos refúgios e estabelecendo-se na região das matas intocadas (MOTA, 1997, p.192-193). Os mineiros vindos de várias partes do Brasil, especialmente do estado de São Paulo, foram estabelecendo-se na margem esquerda do Tibagi.

Dá-se início neste momento a fase da mineração, a qual favoreceu a ocupação e surgimento de povoados a margem deste rio. Começa a implantação de sesmarias em terras tibagianas, com a finalidade de "lavrá-las e semeá-las a fim de assegurarem seu domínio" (RITTER, 1980, p.12). Na região dos Campos Gerais, a maioria das fazendas foi obtida através da doação de sesmarias, nas quais desenvolvia-se atividades pecuárias (RITTER, 1980, p.144). Segundo Mercer e Mercer (1977), Ritter (1980), Eidam (1998) e Lopes (2002), muitos paulistas passaram a ser dono destas concessões em terras do sertão tibagiano, o qual estava dividido em 20 (vinte) sesmarias.

Como forma de completar a renda da mineração, passou-se ao desenvolvimento de atividades criatórias: "Aqueles que se dedicavam à mineração fundavam arraiais e estabeleciam pequenos sítios para criação e invernagem do gado" (EIDAM, 1998, p. 29). No início do século $\mathrm{XX}$, a região apresentava uma série de caminhos que ligavam as áreas criadoras de muares as feiras de Sorocaba e São Paulo, onde estes eram comercializados. Tibagi, apesar de não fazer parte especificadamente do caminho das tropas, muitas vezes servia de pouso para as mesmas. Assim, a atividade pastoril influiu decisivamente na concentração da população em certos locais próximos a estradas por onde as passavam as tropas.

Neste contexto, as terras do Município de Tibagi começam a ter destaque no início do século XX. Tinha-se na região um movimento expansionista, favorecido pela passagem das 
tropas de porcos. Nesta época, as localidades rurais apresentam características peculiares ao "Sistema Faxinal", como a criação de suínos soltos ao redor das casas, alimentando-se do que a natureza lhes oferecia e também de milho para atingirem o peso desejado. (EIDAM, 1998).

\begin{abstract}
O último movimento de expansão das populações dos Campos Gerais foi feita na direção de Tibagi [...] Tibagi foi a partir da segunda década deste século, etapa principal de uma pequena região pioneira [...] Tibagi tinha então, as maiores vendas dos Campos Gerais paranaenses, depois de Ponta Grossa. Ela exercia função de centro de mineração e de lugar e baldeação nos transportes. De Ponta Grossa a Tibagi, podia-se viajar de automóvel; de lá para Ortigueira, ia-se de carroça, e daí em diante, para o Sertão; partiam de Tibagi tropas que chegavam até o Faxinal, Faxinal este chamado de São Sebastião [....] A frente pioneira era formada pelos 'safristas' (criadores de porcos). (BALHANA,1969, p. 49).
\end{abstract}

Não tendo data precisa em relação ao início de sua exploração, sabe-se que se desenvolveu na região intensa atividade extrativa de mate, atividade que permanece até os dias atuais, porém, em menor escala. Mercer e Mercer nos dizem que: "A erva-mate matou o nosso progresso e a madeira andou de parceira [...] ficamos a podar erveiras nativas e derrubar pinheiros que não plantamos [...]” (1977, p. 28).

O município teve uma fase intensa de exploração de madeira, este processo iniciou-se por volta de 1930. "A base da economia foi à madeira, trabalhava-se com madeira de lei, de destaque o pinheiro e a imbuia, devido a abundância desse tipo de madeira encontrada na região" (EIDAM, 1998, p. 59).

Em decorrência deste fato, instalaram-se na região grandes serrarias; a madeira servia para abastecer grandes centros de comercialização, indústrias moveleiras e a construção civil, a qual ganhava destaque devido ao plano de modernização do Presidente Juscelino Kubstchek (EIDAM, 1998). Também vale destacar que nesta mesma época temos o surgimento da Klabin Papel e Celulose, a qual se utilizava de madeiras extraídas desta região como sua principal matéria prima (BALHANA, 1969).

Paralelamente as atividades citadas anteriormente, desenvolvia-se o cultivo da mandioca, a qual estava voltada a atender a demanda das atafonas (moinho manual ou movido por cavalgaduras) que existiam na região, nas quais se extraiam a farinha e o polvilho, produtos que se tornaram tradicionais de Tibagi (EIDAM, 1998). 
Na década de 1970 a cidade de Tibagi começa a receber migrantes da zona rural, muitos dos quais atraídos pelas oportunidades de emprego oferecidas pela implantação da Cooperativa Batavo, a qual ocupou por muito tempo uma grande faixa da estrada de ligação entre Tibagi e Ponta Grossa. Juntamente a este processo teve-se a migração de holandeses dos municípios de Castro e Carambeí, os quais estabelecem suas fazendas ao longo da rodovia que liga Tibagi a Castro (PDMT, 2006). A economia local se voltou para a criação extensiva de bovinos, seguindo-se a agricultura mecanizada, principalmente de soja e milho.

Hoje em dia, pode-se dizer que a distribuição de terras no Município de Tibagi é bastante desigual e há uma grande concentração de renda. A lucratividade com a plantação de grãos (soja) é bastante elevada e vem sendo investida na aquisição de mais terras. Enquanto isso, as formas tradicionais de agricultura, como por exemplo, a familiar, se desfaz devido ao alto preço da terra, da produção e por falta de incentivos governamentais. As propriedades que resistem, acabam caindo nas mãos de empresas fumajeiras, de reflorestadoras ou tornamse agregados de empresas como a Perdigão na criação de suínos ou aves (PDMT, 2006).

O município de Tibagi apresenta de um lado grandes latifúndios e de outro, pequenas propriedades voltadas à agricultura familiar. Os grandes latifúndios situados a leste da rodovia BR-153 (Transbrasiliana) têm por objetivo atender a demanda da Cooperativa Batavo ou o mercado de exportação, sendo 60\% área de cultivo em Tibagi corresponde a plantações de soja. Já as terras situadas a oeste da rodovia BR-153, que fazem parte dos distritos de Alto do Amparo e Caetano Mendes, estão voltadas à pequena propriedade, as quais atendem a demanda principalmente de empresas fumajeiras, reflorestadoras ou agroindústrias.

A observação da estrutura de povoamento do Município de Tibagi (PR), (Figura 01) deixa claramente transparecer uma estrutura dual de ocupação. Esta estrutura dual apresenta como marco divisor o Rio Tibagi. Do lado direito do rio, a ausência de povoados é o retrato do predomínio de grandes fazendas de produção que se estendem, sobretudo, a partir dos municípios de Carambeí e Castro. Do lado esquerdo do Rio, principalmente na porção oeste da BR-153, a concentração de pequenos povoamentos indica a presença de comunidades rurais diferenciadas. 


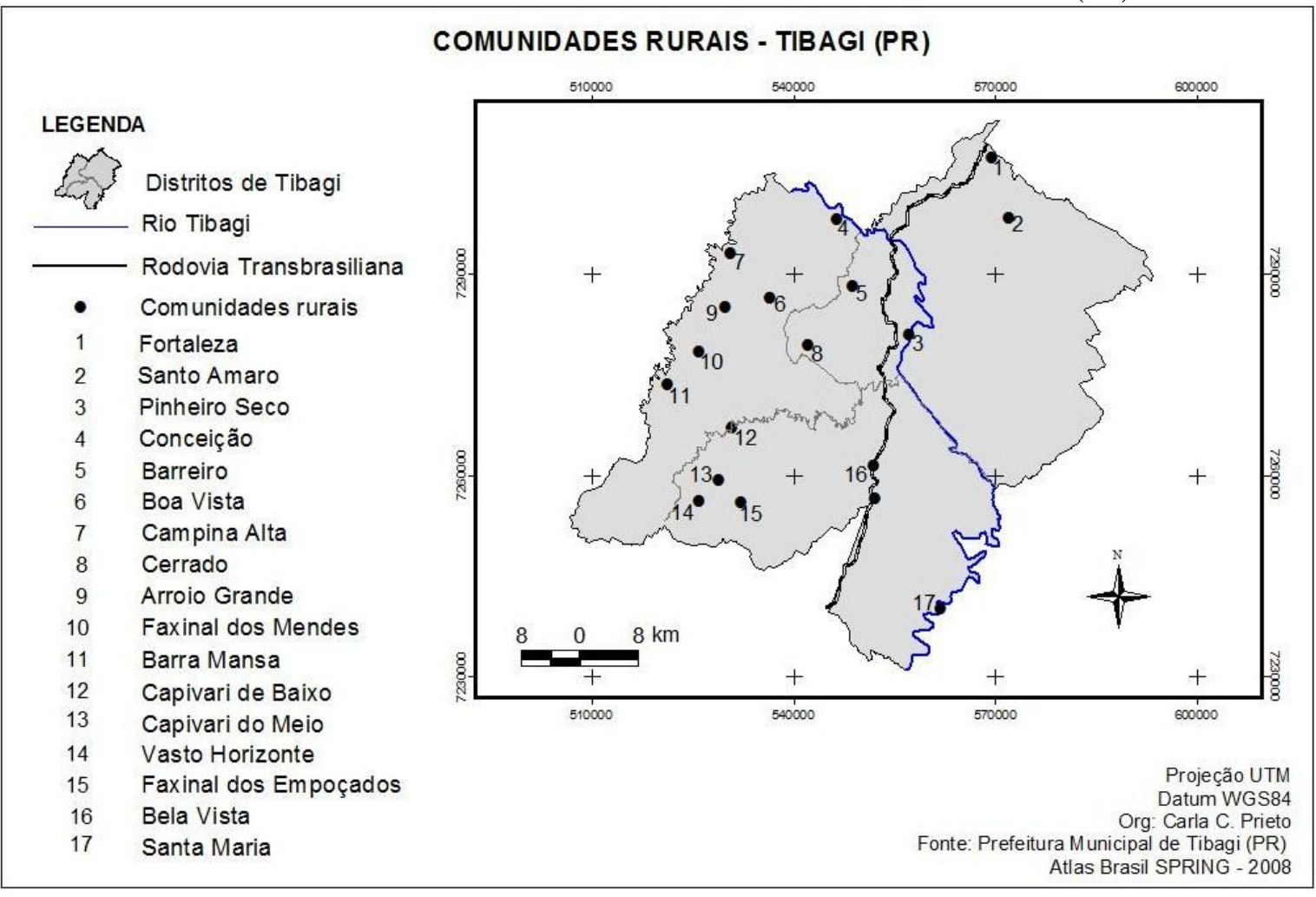

Estas características identificadas na atualidade do Município de Tibagi são resultados de processos sócio-espaciais vivenciados na região e que tiveram como pano de fundo o complexo ambiente de campos e florestas. Assim, a dualidade da paisagem natural transformou-se numa dualidade também da gênese de povoamento. Enquanto no ambiente de Campos, localizado na porção leste do atual município, teve seu processo de ocupação vinculado à instalação de grandes sesmarias, a porção oeste, recoberta por Floresta com Araucária teve seu povoamento vinculado a implantação de comunidades de pequenos agricultores, resultantes da ocupação de índios e colonos, entre estas comunidades, muitas eram faxinais. 


\section{OS FAXINAIS NO MUNICÍPIO DE TIBAGI (PR): A DESAGREGAÇÃO DE UMA TRADIÇÃO - UM ESTUDO SOBRE O FAXINAL DOS EMPOÇADOS}

Na dinâmica econômica vivenciada pelo Município de Tibagi (PR), desde os seus primórdios até a atualidade, as comunidades de faxinal apresentaram seu auge no período do Tropeirismo de Porco. A partir de então, os processos de modernização da agricultura e da sociedade foram introduzindo modelos homogeneizantes que pouco lugar deixava a comunidades tradicionais, levando a uma desagregação desta tradição.

A comunidade de Faxinal dos Empoçados, também conhecida por Faxinal dos Papudos, localiza-se no Distrito do Alto do Amparo, Município de Tibagi Paraná (Figura 02).

FIGURA 02: LOCALIZAÇÃO DO FAXINAL DOS EMPOÇADOS - TIBAGI (PR)

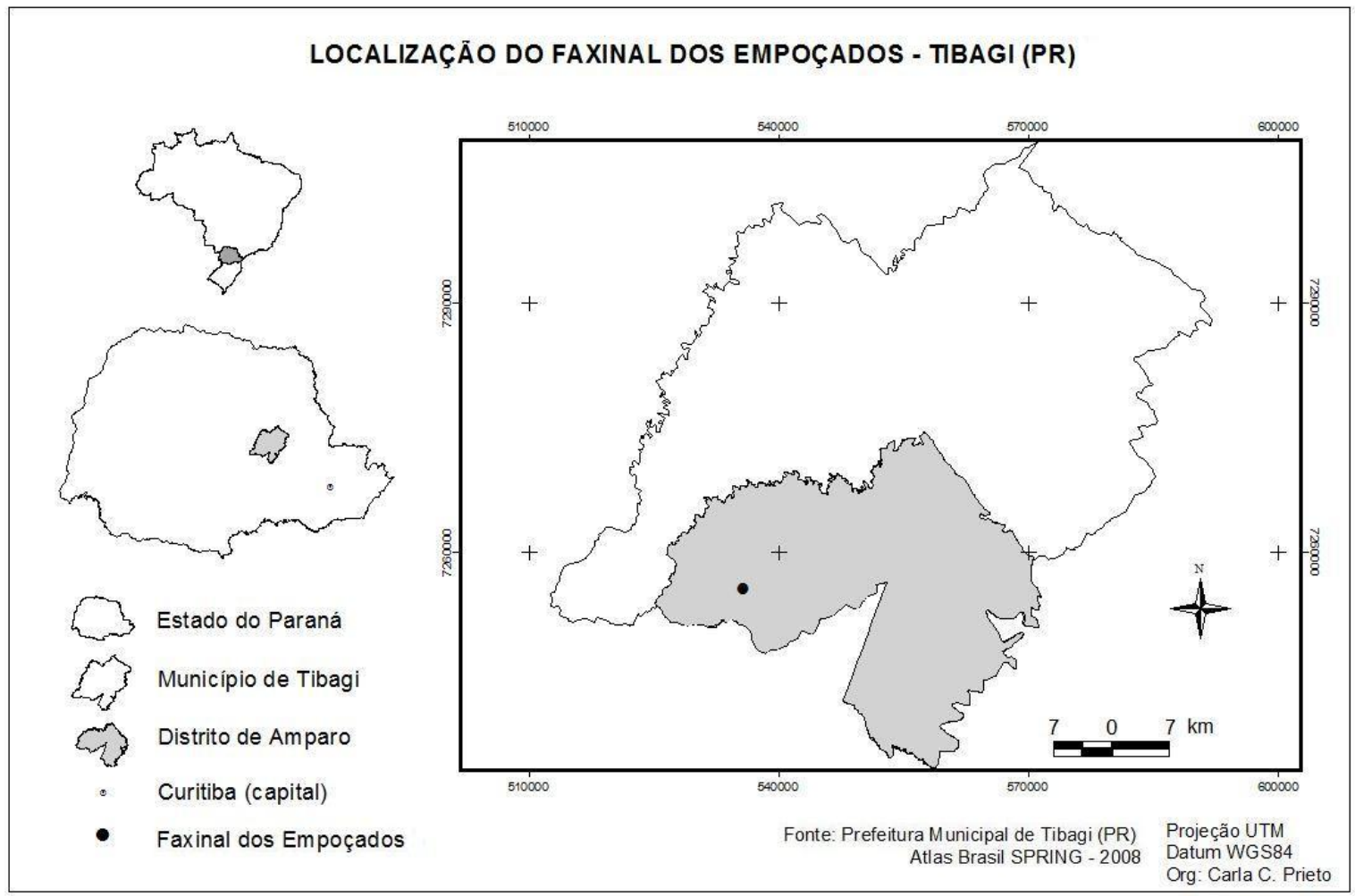

No início da estruturação desta comunidade, existiam apenas seis famílias, sendo que a descendência variava entre indígenas, imigrantes europeus e caboclos. Nesta época, todos os moradores da comunidade viviam de forma bastante harmônica, praticavam uma agricultura voltado ao consumo próprio e trocavam produtos entre si. O espaço de cada família era 
bastante amplo; as terras em abundância favoreciam o desenvolvimento das atividades agrícolas ou pastoris sem a preocupação com reservas de terras para outros fins. No decorrer dos anos de 1950 a 1970 surgem mais famílias de imigrantes europeus, os quais começam a transformar o modo simples de viver desta comunidade.

A sobrevivência da população local dependeu sempre das atividades agrícolas. No início desenvolvia-se apenas uma agricultura de subsistência, onde os principais produtos plantados eram: milho, arroz, feijão, mandioca e pepino. Alguns destes produtos eram vendidos ou trocados nas vendas que existiam na região. Nas vendas eram oferecidos a comunidade outros produtos como: tecidos, panelas, café, açúcar, sal e outros, enfim, produtos necessários à organização do cotidiano doméstico, os quais eram vendidos a granel. As trocas de produtos eram comuns devido à baixa rotatividade de dinheiro.

A extração da erva mate foi à base da economia local por muitos anos. Nas fases de extração do mate era tudo bem rudimentar, colheita feita à mão; carijo ou fornalha construídos de forma bem simples:

Muita gente ia pro mato colher a erva-mate, traziam os feixes que eram sapecados no carijo ou na fornalha, depois repassava pra um responsável para vender, era difícil, os que iam pra poda, voltavam com as mãos todas cortadas, calejadas.... tomávamos bastante chimarrão, mate... (SUEIRO, 2008).

As roças de milho, além de integrarem parte da alimentação da comunidade, serviam de alimento para os amimais, especialmente para os porcos. "Quando o milharal estava na época boa da colheita se soltava os porcos na roça e debuiava os milhos nas costas deles, era uma festa!" (SUEIRO, 2008). Muitas vezes eram realizados mutirões para a limpeza das roças; as pessoas que participavam destes mutirões não recebiam dinheiro em troca de seu serviço; eram recompensados com um baile no final de semana, "[...] se trabalhava, às vezes, a semana inteira para ir no baile no sábado a noite ver a meninada bonita, um tempo muito bom" (SUEIRO, 2008).

Alguns animais de pequeno porte eram criados soltos, como é o caso de galinhas, porcos e outros que se criavam soltos no campo e buscavam sua própria alimentação no meio. Os porcos serviam de alimento para a população local e para a produção de banha, nesta época o óleo nem era usado. 
O porco se criava solto, comia de tudo que achava no mato. Às vezes quando se matava um, ficava com metade, fazia toicinho e a outra parte trocava com o dono da venda, só usávamos a banha, não se conhecia o azeite, o óleo... (SUEIRO, 2008).

As criações de porco sustentaram por anos a economia local; homens se dedicavam ao Tropeirismo de Porco, sendo conhecidos por safristas. A figura do safrista era comum na região; muitas tropas cortavam pelos campos e estradas da comunidade. Existiam na localidade vendas preparadas com estrutura de descanso para o Tropeiro. As tropas em sua maioria seguiam de Candido de Abreu até Ponta Grossa ou tomavam outros destinos como Castro e Jaguariaíva.

Toda casa de comércio tinha um poço na frente, para carroceiros se servir daquela água, além disso, muitas delas possuíam mangueirão de porco. Alguns viajavam de carroça e para pousarem, darem água para os animais e para descansar chegavam nas vendas que tinham estrutura para sua tropa não se dispersar, era onde se abasteciam. Pousavam em suas carroças com toldos ou no paiol dos armazéns, saindo de madrugada com a safra de porcos; descansavam quando o sol estava forte para o animal não morrer. As tropas de porco, normalmente seguiam durante a noite. (EIDAM, 2008).

Outros animais, como vaca, carneiros e cavalos também eram criados; e alguns, como é o caso dos cavalos, serviam como meio de transporte, sendo que a carroça foi o meio de transporte mais comum na região.

No que diz respeito às atividades agrícolas, o cultivo da mandioca também foi importante fonte de geração de renda. Muitas famílias se dedicavam ao cultivo deste produto para atender a demanda da produção da farinha de polvilho. Na região existiam várias atafonas, que eram moinhos movidos a cavalgaduras usados no processo de fabricação da farinha; este produto ganhou destaque pela intensa produção, não só na comunidade, mas em todo o município de Tibagi (PR), o qual acabou sendo reconhecido como um produto típico, fazendo parte da cultura tibagiana.

Houve na região uma fase intensa exploração madeireira. As grandes serrarias que se instalaram no lugar, depredaram praticamente toda a Mata de Araucária. Após a intensa exploração, estas serrarias acabaram fechando; a exploração madeireira que sustentou a economia local acabou deixando para traz agricultores miseráveis. Estes se dedicaram anos ao 
corte de árvores que forneciam madeiras de lei (Imbuía e Pinheiro); e juntamente com isso acabaram com os ervais nativos da região de Matas Mistas com Araucárias.

A extração da madeira contribuiu de forma significativa para a economia local. Acredita-se que a exploração começou por volta de 1930; era um trabalho bastante exaustivo, usado a força dos homens e dos animais. Tudo era cerrado por serra americana ou na base do machado; depois era transportado por animais, só mais tarde é que apareceu o trator e o caminhão. Destacou-se na região as Serrarias ou madeireiras, como a Rocopinnus, Wagner e outras (EIDAM, 2008).

Na década de 1960, instala-se na região a empresa klabin Papel e Celulose, aumentando a demanda por madeiras e na sequência iniciando o processo de reflorestamento na região. Atualmente boa parte dos agricultores mantém em suas propriedades áreas de reflorestamento pertencentes à Klabin; e também muitas áreas foram incorporadas ao patrimônio desta empresa através da aquisição de frações de terra na localidade. O reflorestamento acabou se tornando a principal fonte de renda para muitas pessoas.

Este momento pode ser apontado como o agente desagregador das estruturas do Sistema Faxinal na comunidade rural em estudo. A partir de então, muitos dos pequenos agricultores começaram a vender pequenas frações de terras a grandes proprietários; estes iam anexando a terra adquirida a seus grandes latifúndios. Aos pequenos proprietários restava-lhes uma pequena parcela de terra, sobre a qual se encontrava apenas suas casas e o espaço para uma pequena roça.

Com a desestruturação deste modo de viver, muitos agricultores passaram a buscar novas formas de sobrevivência e acabaram empregando-se em grandes fazendas, se tornando trabalhadores assalariados.

Os agricultores que permaneceram com suas pequenas propriedades, acabaram não resistindo às pressões do mercado capitalista e atualmente atendem a demanda de empresas de reflorestamento ou fumageiras. Com estas desenvolvem processos homogeneizantes, deixando para trás um passado de harmonia, esquecendo uma cultura singular.

Hoje em dia, com as estufas de fumo, não temos mais tempo pra mais nada, o fumo precisa de muito cuidado, tem que vijiá a estufa dia e noite, nem dá pra sair se divertir... antes íamos em festas, se realiza mutirão, era tudo mais unido, tinha festas 
e rezas na igreja, hoje em dia até tem alguma coisa mais não é como antigamente, tudo mudou, a gente quase não vai" (SUEIRO, 2008).

As festas, novenas, rezas e procissões na igreja eram comuns, não podendo se esquecer da famosa Dança de São Gonçalo. Era comum as moças que já estavam passando da idade de casar entrar nesta dança.

\begin{abstract}
As solteironas eram as primeiras a querer a dançar, na hora da dança não podia dar as costas para o santo; tinha uma fila de moças e outra de rapaz, geralmente tentavase dançar com o futuro pretendente, era conhecida como a dança de São Gonçalo Casamenteiro; depois no baile tinha licor e um sequilho muito bom... o baile ia a noite inteira... (SUEIRO, 2008).
\end{abstract}

A religiosidade aliada à diversão mantinha as relações sociais na época; bailes, rezas eram elementos tradicionais na vida quotidiana, mantendo relações de harmonia em toda a comunidade.

Atualmente esta comunidade não apresenta mais os elementos típicos da estrutura Faxinal como apresentava no passado. Nos estudos realizados sobre Faxinais no Paraná esta comunidade, bem como outras comunidades que tiveram sua gênese como faxinal no Município de Tibagi, representam uma lacuna nos levantamentos até agora efetuado. A comunidade não chega a constar como um Faxinal desagregado. A localidade transformou-se em propriedades particulares; algumas fazendas de criação e pastagem de gado ou plantação de soja. Pequenos produtores que continuaram no local sobrevivem subordinados a agroindústria do fumo ou a áreas de reflorestamento. Criadouro comum, terras de plantar, são elementos que restaram somente na lembrança das pessoas que vivenciaram este tempo.

\title{
CONSIDERAÇÕES FINAIS
}

Diante das constatações reveladas por este artigo torna-se necessário preocupar-se com a proteção da identidade de comunidades tradicionais, visando identificar e conhecer os sistemas existentes e, conseqüentemente, buscar alternativas para minimizar os problemas que têm levado à instabilidade e desestruturação das mesmas. 
A concentração de renda nas mãos de poucos, a expropriação do capital e a expulsão de antigos moradores campesinos, bem como a intensificação do uso de novas tecnologias no campo, dispensadoras do trabalho humano, leva ao fenômeno de migração do campo para cidade; gerando assim uma série de problemas que repercutem na vida da sociedade.

Investimentos e diretrizes se fazem necessárias no momento em que se discute sobre a permanência do pequeno agricultor no campo e da valorização da agricultura familiar como forma de promover um desenvolvimento territorial sustentável. A unidade familiar constituise como umas das formas de relações mais simples, singular e bastante utilizada no sistema agrário brasileiro. É preciso conservar esta relação para que o pequeno produtor agrícola não acabe caindo nas mãos de grandes latifundiários, tornando-se trabalhador assalariado e mãode-obra barata, passíveis de exploração. Nestas condições temos a deteriorização da qualidade de vida dos pequenos agricultores; sem falar em situações, onde na tentativa de melhorar de vida, muitos acabam agregando-se a grandes empresas. Nesta tentativa, assumem dívidas e passam anos trabalhando para pagá-la.

Com a intensa exploração dos recursos naturais em determinadas comunidades ditas tradicionais, sua população vêem perdendo seus laços com o passado, deixando para traz todo o conhecimento acumulado e repassado de geração para geração. A sustentabilidade da vida e da biodiversidade é fundamental para reter o pequeno produtor e sua família no ambiente rural, sendo importante buscar o aumento da consciência do homem do campo para a preservação da biodiversidade e das tradições culturais. Considerando o valor social, econômico, cultural e ecológico das comunidades tradicionais, iniciativas tornam-se necessárias para a preservação e manutenção desses espaços. Com essas medidas criar-se-ia um ambiente rural típico a ser explorado como potencial atrativo turístico, gerando renda para os agricultores e fortalecendo as bases turísticas dentro do município no qual a comunidade encontra-se inserida. Portanto, este estudo se apresentou como uma contribuição para despertar reflexões e questionamentos, pois os Faxinais conservam valores da nossa biodiversidade regional e da cultura local, que em outras localidades já não são mais encontradas e que necessitam de ações urgentes para que não ampliem a lista de extintos. 


\section{REFERÊNCIAS}

BALHANA, Altiva Pilati. História do Paraná. Curitiba: Grafipar, 1969. 198 p. (volume 1).

BARBOSA, Tiago Augusto. Território e Territorialidades do Sistema Faxinal: Análise a partir da reconstrução histórica familiar na comunidade Taquari dos Ribeiros em Rio Azul PR. 2007, 85p. Trabalho de Conclusão de Curso (Bacharelado em Geografia) - Universidade Estadual de Ponta Grossa, Ponta Grossa - PR, 2007.

BARRETO, Marcelo; LÖWEN SAHR, Cicilian Luiza. Os faxinais e erva-mate: a incorporação da produção camponesa ao movimento da indústria capitalista.Terr@ Plural, Ponta Grossa, 1 (2), p: 73-83, 2007.

CHANG, Man Yu. Faxinais no Paraná. Informe de Pesquisa. Curitiba, v. 12, nº 80, março, 1988a. 20.p.

Sistema Faxinal: Uma forma de organização Camponesa em desagregação no centro-sul do Paraná. Londrina: IAPAR, 1988b. 124p. (Boletim técnico, 22).

EIDAM, Dircéia. Alto do Amparo: Economia e sociedade - 1950-1970. 1998, 119p. Monografia (Pós-Graduação em História e Sociedade) - Universidade Estadual de Ponta Grossa, Ponta Grossa - PR, 1998.

EIDAM, Dircéia. Entrevista em Comunidades Rurais do Município de Tibagi (PR) (outubro, 2008). Entrevistador: DOUGLAS GRZEBIELUKA. Tibagi: São Bento, 2008. Arquivo mp10. Entrevista concedida por ocasião de encontro com a Professora e Pesquisadora.

DIEGUES, Antônio Carlos; VIANA, Virgílio M. (Orgs.). Comunidades Tradicionais e Manejo dos Recursos Naturais da Mata Atlântica. $2^{\text {a }}$ ed. São Paulo: HUCITEC: NUPAUB: CEC, 2004. 273p.

FERREIRA, Patrícia. Estudo sobre os Faxinais Lageado de Baixo e Lageado dos Mello pr: a construção de conhecimento a partir da ecologia social como subsídio para um projeto de turismo comunitário. 2008, 123p. (Dissertação de Mestrado) - Universidade Estadual de Ponta Grossa, PR, Ponta Grossa, 2008.

LOPES, José Carlos Veiga. Introdução à história de Tibagi. Curitiba: J.C.V. Lopes, 2002. $197 \mathrm{p}$.

LÖWEN SAHR, Cicilian Luiza. O Pré-Moderno na Pós-Modernidade: refletindo sobre as comunidades de Faxinais da Floresta com Araucária do Paraná. In: MARAFON, Gláucio José; RUA, João; RIBEIRO, Miguel Ângelo. Abordagens teórico-metodológicas em Geografia Agrária. Rio de Janeiro: Eduerg, 2007. p. 207-223.

LÖWEN SAHR, Cicilian Luiza; CUNHA, Luiz Alexandre Gonçalves. O significado social e ecológico dos Faxinais: Reflexões acerca de uma política agrária sustentável para a região da mata com araucária no Paraná. Emancipação, Ponta Grossa, 5 (1), p: 89-104, 2005.

LÖWEN SAHR, C. L.; IEGELSKI, F. O Sistema Faxinal no Município de Ponta Grossa: diretrizes para preservação do ecossistema, do modo de vida, da cultura e das identidades das 
comunidades e dos espaços faxinalenses. Ponta Grossa, 2003. 108 p. (Relatório Técnico) Prefeitura Municipal de Ponta Grossa.

MARQUES, Cláudio Luiz G. Levantamento Preliminar Sobre Sistema Faxinal: Relatório Final. Curitiba: IAP - PR, 2004. 193p.

MERCER, Edmundo Alberto; MERCER, Luiz Leoplodo. História de Tibagi. Curitiba: Cenicom, 1977. 196 p.

MOTA, Lúcio Tadeu. A guerra de conquista nos territórios dos índios Kaingang do Tibagi. Revista de História Regional. Ponta Grossa, v. 2, n. 1, p: 187 - 207, 1997.

PDMT. Plano Diretor Municipal de Tibagi. 2006.

RITTER, Marina Lourdes. As sesmarias do Paraná no século XVIII. Curitiba: Instituto Histórico, Geográfico e Etnográfico Paranaense, 1980. 250 p

SCHUSTER, Wladimir Teixeira. Articulações entre transformações no uso da terra e (des)agregação no modo de vida: Reflexões sobre o Faxinal Saudade Santa Anita Turvo PR. 2007, 58p. Trabalho de Conclusão de Curso (Bacharelado em Geografia) - Universidade Estadual de Ponta Grossa, Ponta Grossa - PR, 2007.

SOUZA, Marcelo Lopes de. Mudar a Cidade - Uma introdução crítica ao Planejamento e à Gestão Urbanos. Rio de Janeiro: Bertrand, 2006.

SOUZA, Roberto M. de. Transformações Econômicas e Sociais e Trajetória na Agricultura Familiar: Estudo de Caso sobre a Desconstrução da Autonomia da Agricultura Familiar no Faxinal Saudade Santa Anita, Turvo - PR. 2001, 135 p. (Dissertação de Mestrado) - UFSM , RS, Santa Maria, 2001.

"SPRING: Integrating remote sensing and GIS by object-oriented data modelling" Camara G, Souza RCM, Freitas UM, Garrido J Computers \& Graphics, 20: (3) 395-403, May-Jun 1996.

SUEIRO, João Vanir. Entrevista em Comunidades Rurais do Município de Tibagi (PR) (outubro, 2008). Entrevistador: DOUGLAS GRZEBIELUKA. Tibagi: Faxinal dos Empoçados, 2008. Arquivo mp10. Entrevista concedida durante visita a comunidade do Faxinal dos Empoçados.

(Recebido em dezembro/08. Aceito em março/09) 